Article

\title{
Reliability Analysis of Free Jet Scour Below Dams
}

\section{Chuanqi Li *, Shuai Wang and Wei Wang}

School of Civil Engineering, Shandong University, Jinan 250014, China;

E-Mails: wangshuaisdu@126.com (S.W.); wangweilcq@sdu.edu.cn (W.W.)

* Author to whom correspondence should be addressed; E-Mail: lichuanqi@sdu.edu.cn; Tel.: +86-531-8839-2789; Fax: +86-531-8839-3861.

Received: 29 October 2012; in revised form: 3 December 2012 / Accepted: 11 December 2012 / Published: 14 December 2012

\begin{abstract}
Current formulas for calculating scour depth below of a free over fall are mostly deterministic in nature and do not adequately consider the uncertainties of various scouring parameters. A reliability-based assessment of scour, taking into account uncertainties of parameters and coefficients involved, should be performed. This paper studies the reliability of a dam foundation under the threat of scour. A model for calculating the reliability of scour and estimating the probability of failure of the dam foundation subjected to scour is presented. The Maximum Entropy Method is applied to construct the probability density function (PDF) of the performance function subject to the moment constraints. Monte Carlo simulation (MCS) is applied for uncertainty analysis. An example is considered, and there liability of its scour is computed, the influence of various random variables on the probability failure is analyzed.
\end{abstract}

Keywords: free over fall jet; scour; reliability analysis; maximum entropy method; Monte Carlo simulation

\section{Introduction}

Scour downstream of dams is one of the main concerns in hydraulic engineering. The transfer of water to the downstream river may scour the dam foundation and the downstream riverbed. In the long term, this scour process may create structural safety problems. Hence, accurate predictions of time evolution and ultimate scour depth are required [1]. A number of equations and models have been developed in the past to predict the potential free jet scour depth below dams and several studies have 
been carried out to estimate downstream scour below dams [2-6].These scour prediction equations are deterministic in nature, and do not account for the uncertainties of the parameters involved in the scour depth equations. Today's most popular evaluation methods are of empirical and semi empirical nature. They do not fully describe the physical background of the phenomenon. A physical based scour prediction model, the Comprehensive Scour Model, has been developed based on a parametric description of the main physical processes responsible for scour [7-8].The physically based approach gives a much more reliable scour estimation than simple empirical formulas.

The inherent uncertainties in various model parameters suggest that dam foundation safety would be ensured in a probabilistic sense. Reliability analysis basically provides a quantitative estimation of dam safety against scouring. Several authors have addressed reliability analysis of scouring in recent years. Muzzammil has presented a methodology for the reliability assessment of scour downstream of a ski-jump bucket using the first-order reliability method (FORM) [9]. Yanmaz has assessed the reliability of the scouring of foundations downstream of outlet facilities [10]; reliability computations are carried out by simulating the safety margin using the Monte Carlo technique. Ghahfarokhi uses the probabilistic method to estimate plunge pool erosion downstream of a ski jump bucket [11]. Hydraulic variables involved in plunge pools, such as discharge, flow depth and velocity, are stochastic in nature, and therefore may be represented by relevant probability distributions.

The maximum entropy method (MEM), which is based on Shannon's measure of uncertainty, has been used for estimating distribution functions [12-14]. MEM is regarded as the most unbiased estimation for the PDF, which means the most probable PDF from all the PDF under the moment's constraint since "it is maximally noncommittal with regard to missing information".

The objective of this study is to present a methodology for quantifying the probability of dam failure due to scour. In order to evaluate the stability of dam foundation, the paper combined the maximum entropy principle with Monte Carlo method. The probability density function (PDF) of performance function is calculated based on maximum-entropy method. Monte Carlo simulation (MCS) is used to generate random samples of the variables according to the given probability distributions.

\section{Scour Model of Free Over Fall Jet}

Free over fall jet scour over the top of arch dams. With free over fall over the top, the jet would fall very near the base of the dam; a deep scour hole (plunge pool) in the riverbed may pose safety problems for the dam foundation. Hydraulic, geotechnical and morphologic factors control the depth of plunge pool. The mechanism of scour is an extremely complex process due to the influence of various hydraulic, hydrological and geological factors. There are many formulae developed over the years to predict the maximum scour depth downstream of a hydraulic structure. No formulas are presently available to accurately determine the maximum depth of the plunge pool. However, based on laboratory studies and field information obtained in several projects, a number of empirical formulas have been developed for predicting the maximum depth of scour of a stable plunge pool. Among these are the ones proposed by Veronese [15], Mason [16] and Chen [17]. Bollaert [7-8] presents a physically based model for evaluation of rock scour due to high-velocity jet impact.

Figure 1 shows a free jet discharging over a dam. The Veronese equation yields an estimate of scour measured from the tail water surface to the bottom of the plunge pool. This equation is given as: 


$$
d_{m}+t=1.9 q^{0.225} H^{0.54}
$$

where:

$d_{m}$ is the maximum scour depth,

$t$ is the tail water depth,

$q$ is the water discharge per unit width,

$H$ is the elevation difference between reservoir and tail water (total water head).

The Veronose equation was published about 60 years ago and has been recognized as a significant basis for scour depth investigations.

Figure 1. Definition sketch of free over fall jet.

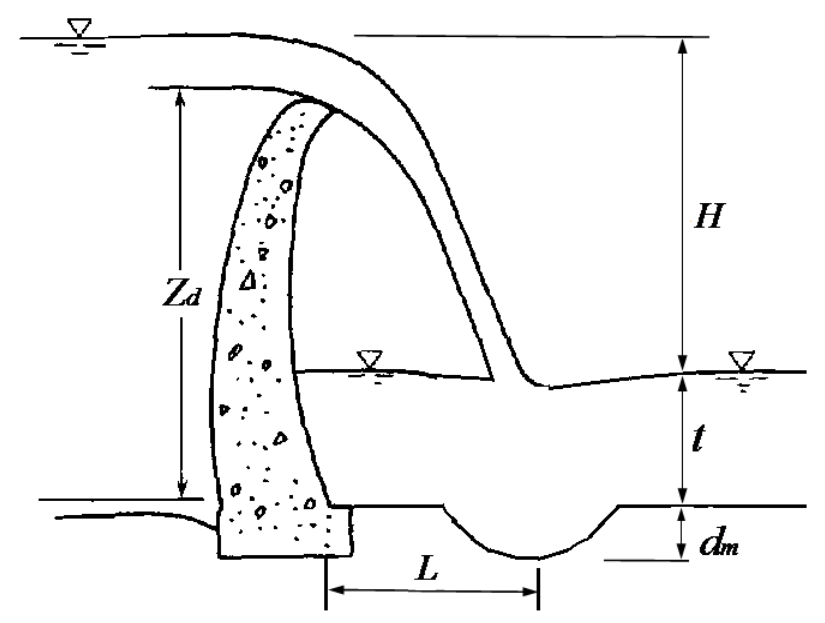

Based on prototype data from dams in China, Chen [17] proposed the following formula:

$$
d_{m}=k q^{0.5} H^{0.25}-t
$$

where $k$ is the scouring coefficient, varying with capacity of rocky riverbed to resist scour, for solid rock $k=0.7 \sim 1.1$ for medium rock $k=1.1 \sim 1.4$, and for soft or broken rock $k=1.4 \sim 1.8$ [18]. $q$ and Hare the same as in Equation (1).Because of its convenient and concise form, formula (2) is widely used in China to estimate the maximum scour depth at downstream of hydraulic structures or spillways.

The distance for maximum scour depth from the dam $(L)$ can be written as a function of the discharge per unit width $(q)$ and the elevation difference $\left(Z_{d}\right)$. According to the Design Specifications for Concrete Arch Dams (SL282-2003), the distance of the maximum scour point is given as follows [19]:

$$
L=2.3 q^{0.54} Z_{d}^{0.19}
$$

where:

$\mathrm{L}$ is the distance of maximum scour point from the dam toe,

$Z_{d}$ is the elevation difference between the top of dam and the riverbed. 


\section{Scouring Reliability of Dam Foundation}

\subsection{Performance Function}

To perform the reliability analysis of foundation scour, the failure and safety state of a dam foundation should be identified via the performance function. A performance function can first be defined as:

$$
Z=g(X)=R(X)-S(X)
$$

where $X=\left(X_{1}, X_{2}, \ldots, X_{n}\right)$ is the vector of the input parameters, $R$ represents the resistance to failure of the structure, $S$ represents the action causing failure. Both the action and resistance are, generally, functions of other basic variables whose probability distributions or statistical properties may be reasonably estimated. $g(X)$ is the performance function with $g(X)>0$ indicating satisfactory performance (stability), $g(X)<0$ indicating unsatisfactory performance (failure), while the limit state is $g(X)=0$.

For the dam foundation safety, it is important to ensure that the scour will not progress upstream to the extent that the safety of the structure might be in danger. The dam foundation safety can be evaluated by using the ratio of the distance for maximum scour depth $(L)$ to the maximum scour depth $\left(d_{m}\right)$. Defining $C=L / d_{m}, C$ can be used as the criterion of the effect of local scour against the stability of dam, and $C$ should be usually more than 3 to 4 to ensure the dam foundation safety [18-19].In this study, the empirical scour model will be used. Depending on the criteria adopted to define the failure of the foundation, the performance function $g(X)$ expresses in terms of margin safety can be defined as:

$$
g(X)=L-C d_{m}=2.3 q^{0.54} Z_{d}^{0.19}-C\left(k q^{0.5} H^{0.25}-t\right)
$$

Hence the reliability of the dam foundation can be defined as:

$$
P_{s}=P(g(X) \geq 0)=P\left(L-C d_{m} \geq 0\right)
$$

In a deterministic approach, the values of $L$ and $d_{m}$ are constant forgiven design conditions and the value of $g(X)$ needs to be greater than zero. In fact, most of the variables affecting scouring are uncertainties. Therefore, for the worst combination of scouring variables, $g(X)$ may attain a negative value.

The failure probability, $P_{f}$, can be expressed in terms of the performance function by the following integral:

$$
P_{f}=1-P_{s}=P(Z=g(X)<0)=\int_{-\infty}^{0} f(Z) d Z
$$

where $f(Z)$ denotes the probability density function (PDF) of the performance function, $Z$, and the integral is carried out over the failure domain. Equation (7) is nonlinear; therefore, an approximate technique should be developed to determine failure probability. 


\subsection{Uncertainty Analysis}

Dam foundations may be seriously scoured under jet action. The degree of scour depends on the characteristics of the jet leaving the top of dams, the depth of the tail water, and the properties of the bed material, which are uncertain in nature. The Equations (2) and (3) are deterministic; they don't account for uncertainties in the model parameters, or the hydraulic variables. In fact, hydraulic variables involved in plunge pools, such as discharge, flow depth, and velocity, are stochastic in nature, which may be represented by relevant probability distributions.

In this study, Monte Carlo simulation (MCS), as a significant sampling technique, is used to quantify the uncertainty of desired uncertain random variables. Monte Carlo simulations a powerful analysis tool that involves a random number generation and simulates the behavior of a variable when the data is insufficient to make decisions. In Monte Carlo simulation, probability distributions are assumed for the uncertain variables for the system being studied. Random values of each of the uncertain variables are generated according to their respective probability distributions.

\section{Maximum Entropy Distribution}

\subsection{Determination of Density Function}

The maximum entropy method is based on the concept that the distribution that maximizes the information entropy is the statistically most likely to occur. Here the maximum entropy method is used to approximate the PDF of the performance function. Shannon [20] defined entropy as a measure of uncertainty about a random variable. Based on the entropy principle proposed by Shannon entropy distributions are defined to be those which maximize the information entropy measure:

$$
H[f(Z)]=-\int_{R} f(Z) \ln [f(Z)] d Z
$$

where $f(Z)$ is the probability density function of the performance function, $Z$, and $R$ is the integral domain.

Jaynes [21] formulated the maximum entropy principle as a rational approach for choosing a consistent probability distribution, amongst all possible distribution, that contains a minimum of spurious information. The principle states that the most unbiased estimate of a probability distribution is that which maximizes the entropy subject to constraints supplied by the available information, e.g., moments of a random variable. The maximum entropy method of estimating $f(Z)$ is stated as follows:

$$
\max H=-\int_{R} f(Z) \ln [f(Z)] d Z
$$

Subject to $\quad \int_{R} f(Z) d Z=1$

$$
\begin{aligned}
& \int_{R} Z f(Z) d Z=\mu_{Z} \\
& \int_{R}\left(Z-\mu_{Z}\right)^{i} f(Z) d Z=\mu_{Z}^{(i)} \quad(i=2,3, \cdots, m)
\end{aligned}
$$


where $\mu_{\mathrm{Z}}$ is the mean value of the performance function, $Z, \mu_{Z}^{(i)}$ denotes the $i$-th central moment of $Z$; $m$ is the number of the given moment constrains. Max means that when the entropy reaches the maximum, we obtain the best probability density function. $f(Z)$ denotes the PDF of $g(X)$ to be determined by the maximum entropy. The optimal solution of Equation (10) is the maximum entropy estimate of $f(Z)$.

In many studies, it was shown that the first four moments are sufficient to describe a wide range of distribution types [22-23]. We use Lagrange's method to solve for the PDF. The solution of Equation (9), subject to Equation (10), can be obtained by using the method of Lagrange multipliers. This yields:

$$
f(Z)=\exp \left[\lambda_{0}+\sum_{i=1}^{4} \lambda_{i}\left(Z-\mu_{Z}\right)^{i}\right]
$$

where $\lambda_{i}, i=0,1,2,3,4$, are Lagrange multipliers, which can be expressed in terms of constraints given by Equation(10).To compute a MEM density, we have to determine the Lagrange multipliers $\lambda_{0}, \lambda_{1}, \cdots, \lambda_{4}$ by the non-linear of equations.

\subsection{Solving the Lagrangian Multipliers}

To find the maximum entropy solution, we have to solve for the Lagrangian multipliers. Five Lagrangian multipliers $\lambda_{i}, i=0,1,2,3,4$, can be obtained by solving the following equations:

$$
\begin{gathered}
\lambda_{0}=-\ln \left\{\int_{R} \exp \left[\sum_{i=1}^{4} \lambda_{i}\left(Z-\mu_{Z}\right)^{i}\right] d Z\right\} \\
\mu_{Z}=\frac{\int_{R} Z \exp \left[\sum_{i=1}^{4} \lambda_{i}\left(Z-\mu_{Z}\right)^{i}\right] d Z}{\int_{R} \exp \left[\sum_{i=1}^{4} \lambda_{i}\left(Z-\mu_{Z}\right)^{i}\right] d Z} \\
\mu_{Z}^{(r)}=\frac{\int_{R}\left(Z-\mu_{Z}\right)^{r} \exp \left[\sum_{i=1}^{4} \lambda_{i}\left(Z-\mu_{Z}\right)^{i}\right] d Z}{\int_{R} \exp \left[\sum_{i=1}^{4} \lambda_{i}\left(Z-\mu_{Z}\right)^{i}\right] d Z} \quad(r=2,3,4)
\end{gathered}
$$

For a more convenient numerical solution, Equation (12) and (13) are changed as follows:

$$
\begin{gathered}
R_{1}=1-\frac{\int_{R} Z \exp \left[\sum_{i=1}^{4} \lambda_{i}\left(Z-\mu_{Z}\right)^{i}\right] d Z}{\mu_{Z} \int_{R} \exp \left[\sum_{i=1}^{4} \lambda_{i}\left(Z-\mu_{Z}\right)^{i}\right] d Z} \\
R_{r}=1-\frac{\int_{R}\left(Z-\mu_{Z}\right)^{r} \exp \left[\sum_{i=1}^{4} \lambda_{i}\left(Z-\mu_{Z}\right)^{i}\right] d Z}{\mu_{Z}^{(r)} \int_{R} \exp \left[\sum_{i=1}^{4} \lambda_{i}\left(Z-\mu_{Z}\right)^{i}\right] d Z} \quad(r=2,3,4)
\end{gathered}
$$

Where the $R_{r}$ are the residuals that are reduced to near zero by a numerical technique. A solution can be obtained by using nonlinear programming to obtain the minimum of the sum of the squares of the residuals: 


$$
\min R^{2}=\sum_{r=1}^{4} R_{r}^{2}
$$

Convergence is achieved when $R^{2}<\varepsilon$, or $\left|R_{r}\right|<\varepsilon$, where $\varepsilon$ is the specified acceptable error. Equation (12) is used to obtain $\lambda_{0}$.

\subsection{Calculation of Failure Probability}

Based on the probability density function $f(Z)$, the failure probability of the dam foundation can be calculated as:

$$
P_{f}=P(Z \leq 0)=\int_{-\infty}^{0} \exp \left[\lambda_{0}+\sum_{i=1}^{4} \lambda_{i}\left(Z-\mu_{Z}\right)^{i}\right] d Z
$$

where $f(Z)$ denotes the probability density function (PDF) of the performance function, $Z$, and the integral is carried out over the failure domain.

\section{Example}

The application example corresponds to the Ertan Dam. A reliability evaluation of the dam foundation subjected to scouring was carried out. The Ertan Damis an arch dam on the Yalong River, a tributary of the Yangtze River in Sichuan Province, southwest China. The Ertan Dam is a $240 \mathrm{~m}$ high and 774.7 long double-curvature arch dam. The dam withholds a normal reservoir of $580 \times 10^{6} \mathrm{~m}^{3}$. The dam has four different ways to discharge water downstream. The dam has the two large spillway tunnels $(13 \mathrm{~m} \times 13.5 \mathrm{~m})$, seven surface spillways, six middle outlets and four bottom outlets. The seven surface spillways can discharge $6,260 \mathrm{~m}^{3} / \mathrm{s}$. In this example, we study the scour of the surface spillways of Ertan dam. The formula for discharge per unit width is[24]:

$$
q=\varepsilon m_{d}\left[0.805+0.245 \frac{H_{W}}{H_{d}}-0.05\left(\frac{H_{W}}{H_{d}}\right)^{2}\right] \sqrt{2 g} H_{W}^{3 / 2}
$$

where:

$$
\begin{aligned}
& \varepsilon \text { is contraction coefficient, } \\
& H_{d} \text { is design water head, } \\
& m_{d} \text { is discharge coefficient corresponding to } H_{d}, m_{d}=0.47 \sim 0.49, \\
& H_{W} \text { is water head over the weir crest. }
\end{aligned}
$$

Three random variables are considered: water level $(H)$, scour coefficient $(k)$ and the downstream water depth $(t) . t$ can be calculated by the downstream water level and the riverbed level. The distributions of three random variables are assumed to obey the normal distribution based on the analysis and study of existing research results [25-27]. The means and standard deviations of the random variables are listed in Table1. 
Table 1. Parameters of random variables.

\begin{tabular}{cccc}
\hline Variables & Distribution & Mean value & Standard deviation \\
\hline Scour coefficient, $k$ & Normal & 1.35 & 0.22 \\
water head, $\mathrm{H}(\mathrm{m})$ & Normal & 202.0 & 3.49 \\
unit discharge, $\mathrm{q}\left(\mathrm{m}^{3} / \mathrm{m} . \mathrm{s}\right)$ & Normal & 60.08 & 1.03 \\
\hline
\end{tabular}

Monte Carlo simulation is used to generate random samples of the variables according to the probability distributions. The values of the variables are randomly generated according to their probability density functions.

The performance function may be written as:

$$
Z=2.3 q^{0.54} Z_{d}^{0.19}-C\left(k q^{0.5} H^{0.25}-t\right)
$$

In this equation, $Z<0$ indicates failure. Considering this single performance function, an estimate is required for the probability $P(Z<0)$. Taking $C$ as 3 , the PDF of the performance function can be expressed as Equation (21) according to the MEM:

$$
f(Z)=\exp \left(-8.1253 Z^{4}-1.7219 Z^{3}+16.6987 Z^{2}+1.8319 Z-8.2044\right)
$$

The probability of failure is:

$$
P_{f}=P(Z \leq 0)=\int_{-\infty}^{0} f(Z) d Z=0.51 \%
$$

To investigate the effect of $k, H$ and $q$ on reliability, different values of $k, H$ and $q$ was taken into account. The variations of the failure probability with respect to the scouring coefficient, discharge per unit width, and water head are shown in Figures 2-4.

Figure 2. Relationship between failure probability and scouring coefficient.

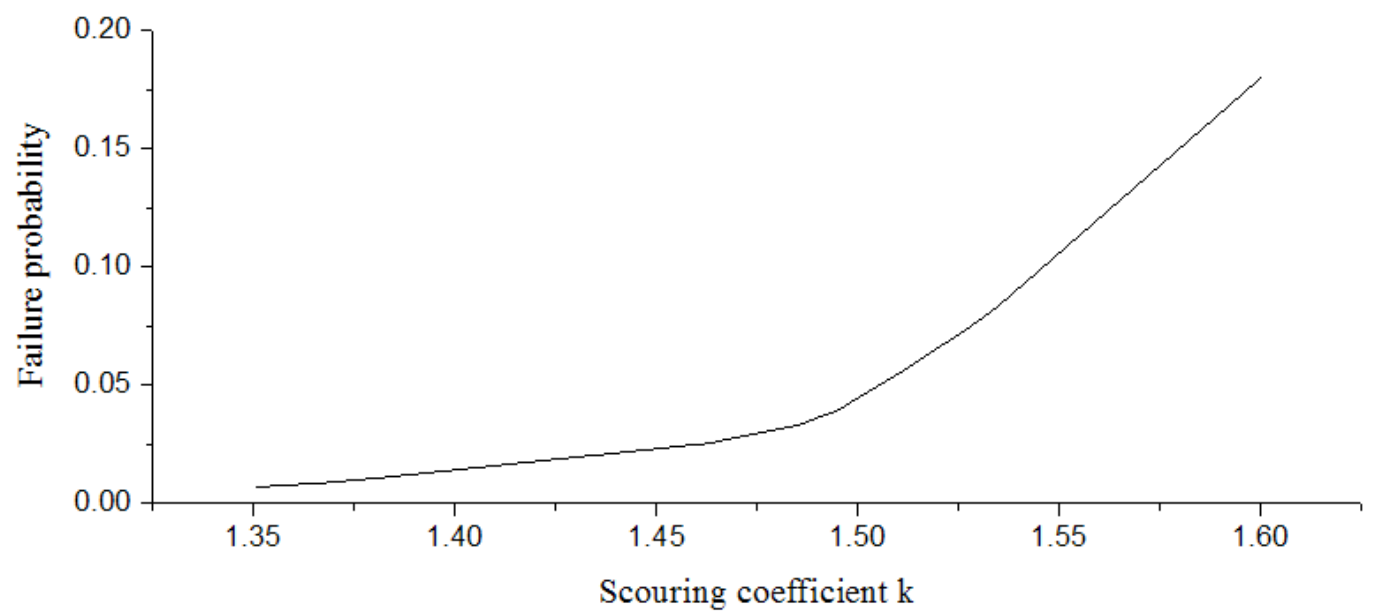


Figure 3. Relationship between failure probability and discharge per unit width.

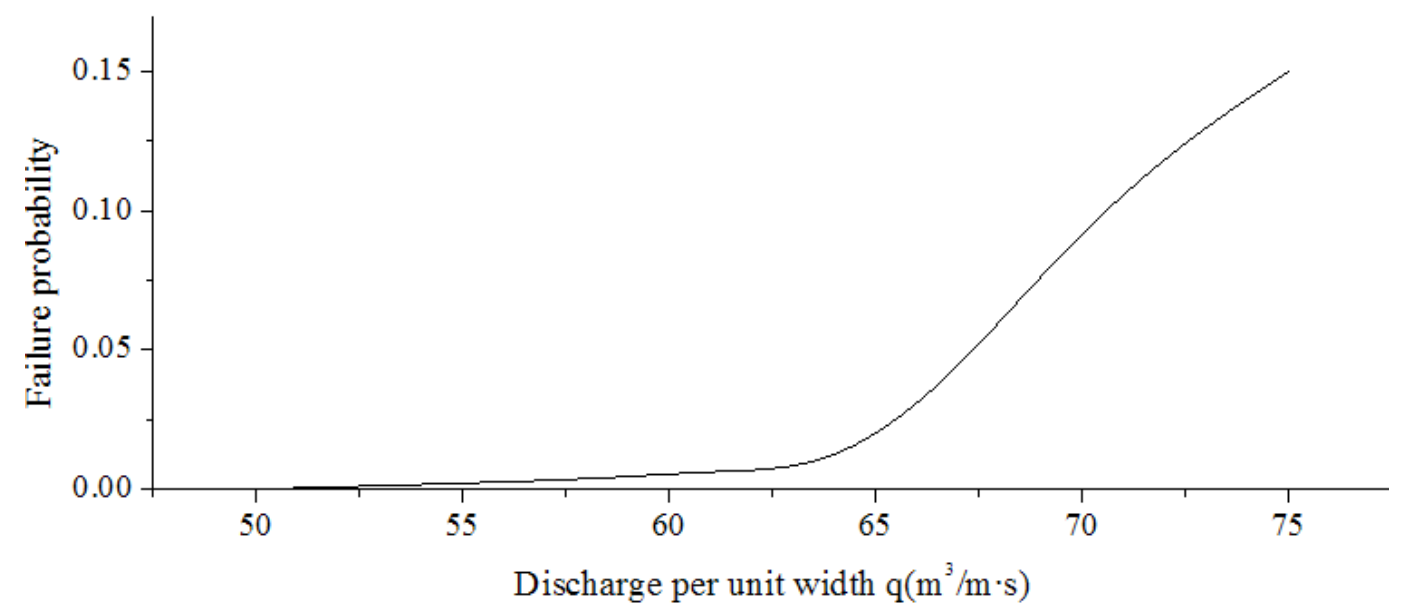

Figure 4. Relationship between failure probability and water head.

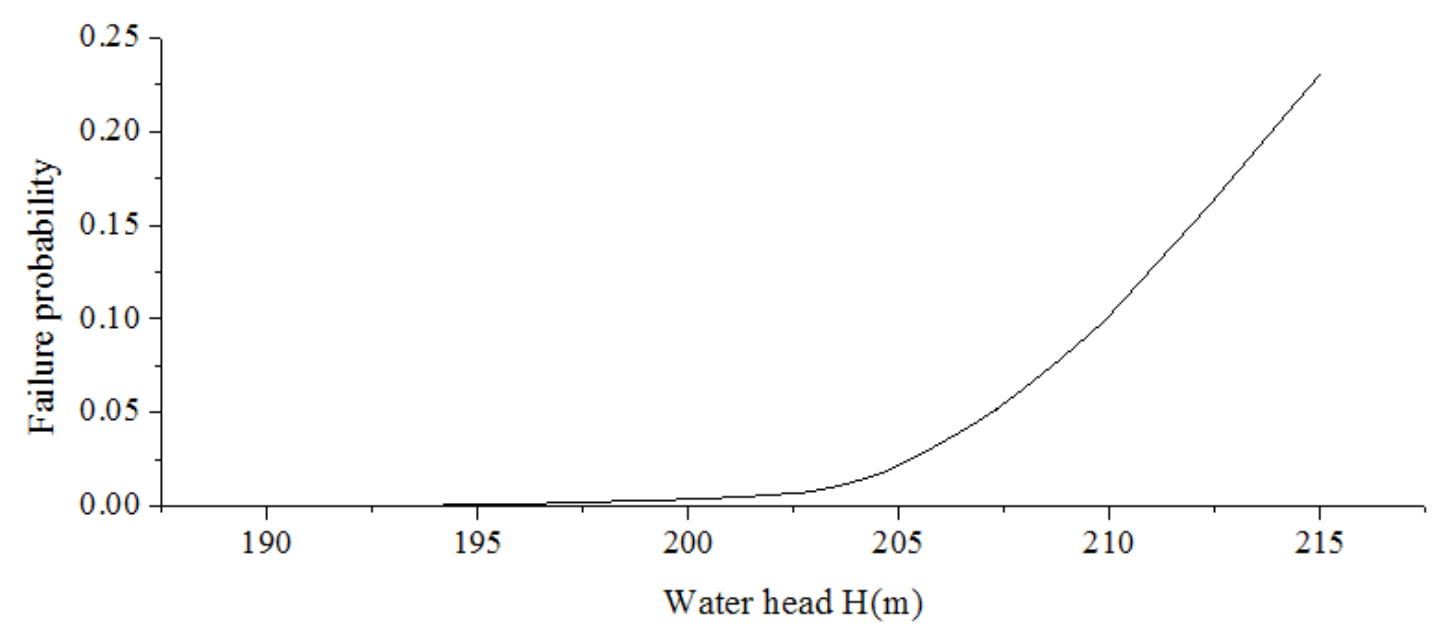

\section{Conclusions}

In this study, a probabilistic model in order to assess the risk of dam foundation failure due to scour action is presented. Uncertainty in the hydraulic variables involved in plunge pools, such as discharge, flow depth, is explicitly considered. Monte Carlo simulation (MCS) is applied to generate a large number of random sample values according to their respective probabilistic distributions. A limit state function has been formulated for the dam foundation safety under jet action. The probability density function (PDF) of the performance function is calculated based on maximum-entropy method (MEM).As an illustration of the developed methodology, a jet scour case example is analyzed. The example demonstrates how the reliability method can be used to evaluate the risk of dam foundations subjected to scour action.

\section{Acknowledgments}

This research was supported in part by the Special Fund for Public Welfare Industry (No. 201301057). 


\section{References}

1. Bollaert, E.F.R.; Schleiss, A.J.Scour of rock due to the impact of plunging high velocity jets Part I: Astate-of-the-art review. J. Hydraul. Res. 2003, 41, 451-464.

2. Bormann N.E.; Julien, P.Y. Scour downstream of grade-control structures. J. Hydr. Engrg. ASCE 1991, 117, 579-594.

3. Azmathullah, H.; Deo, M.C. Neural networks for estimation of scour downstream of ski-jump bucket. J. Hydr. Engrg. ASCE 2005, 131, 898-908.

4. Guven, A.; Gunal, M. Genetic programming approach for prediction of local scour downstream of hydraulic structures. J. Irrigat. Drain Eng. 2008,134, 241-249.

5. Guven, A.; Gunal, M. Prediction of local scour downstream of grade-control structures using neural networks. J. Hydr. Eng. ASCE 2008, 11, 1656-1660.

6. Yildiz, D.; Üzücek, E. Prediction of scour depth from freefalling flip bucket jets. Int. Water Power Dam Constr.1994, 46, 50-56.

7. Bollaert, E.F.R. A comprehensive model to evaluate scour formation in plunge pools. Int. Water Power Dam Constr. 2004, 1, 94-101.

8. Bollaert, E.F.R.; Schleiss, A.J. Physically based model for evaluation of rock scour due to high-velocity jet impact. J. Hydr. Eng. 2005, 131, 153-165.

9. Muzzammil, M.; Siddiqui, N.A. Reliability analysis of scour downstream of a ski-jump bucket. P. I. Civil. Eng. Wat. 2009, 162, 389-398.

10. Yanmaz, A.M. Reliability simulation of scouring downstream of outlet facilities.Turkish. J. Eng.Env. Sci.2003, 27, 65-72.

11. Shams Ghahfarokhi, G.; Phajm van Gelder. Probabilistic description of scour hole downstream of flip bucket spillway of large dams. Technical Proceedings International Conference on Dam and Water for Future (ANCOLD), Gold Coast, Australia, November, 2008.

12. Sobczyk, K.; Trebicki, J. Approximate probability distributions for stochastic systems: Maximum entropy method. Comput. Method Appl. Mech. Eng. 1999, 168, 91-111.

13. Zhang, G.; Zhu, W.; Bai, S. A method of maximum entropy density function for calculation of approximate failure probability (in Chinese). Chin. J. Rock Mech. Eng. 1995, 14, 119-129.

14. Li, C.; Wang, S. Maximum-entropy method for evaluating the slope stability of earth dams. Entropy. 2012, 14, 1864-1876.

15. Veronese, A. Erosioni de Fondo a Valle di unoScarico (in Italian). Annali. dei Lavori. Publicci.1937, 75, 717-726.

16. Mason, P.J.; Arumugam, K. Free jet scour below dams and flip buckets. J. Hydraul. Eng. ASCE 1985, 11, 220-235.

17. Chen, C. On the energy dissipation of high overflow dam with flip bucket and estimation of downstream local erosion (in Chinese). J. Hydraul. Eng.1963, 2, 13-23.

18. Wang, S. A formula for estimating the scour depth of rocky riverbeds by the free jet from a trajectory bucket (in Chinese). J. Hohai. Univ. 1981, 2, 37-56.

19. The professional standards compilation group of People's Republic of China. Title of article. In Design Specification for Concrete Arch Dams (SL282-2003); China Water and Power Press: Beijing, China, 2003; pp. 58-59. 
20. Shannon, C.E. A mathematical theory of communication. Bell Syst. Tech. J. 1948, 27, 379-423.

21. Jaynes, E.T. Information theory and statistical mechanics. Phys. Rev. 1957, 106, 620-630.

22. Zellner, A.; Highfield, R.A. Calculation of maximum entropy distributions and approximation of marginal posterior distributions. J. Econom. 1988, 37, 195-209.

23. Rockinger, M.; Jondeau, E. Entropydensities with an application to autoregressive conditional skewness and kurtosis. J. Econom. 2002, 106, 119-142.

24. Xu, Z.; Guo, Z. Risk calculation of open-type spillway (in Chinese). J. Hydraul. Eng.1989, 4, 50-54.

25. Wu, S.; Zhang, S. Statistic values for yearly maximum of head-water level of dams (in Chinese). J. Hohai. Univ. 1984, 4, 66-74.

26. Xu, Z.; Guo, Z. Reliability analysis of flood relief scheme of Ertan Project (in Chinese). J. Hydraul. Eng. 1990, 8, 48-52.

27. Chu, X. Research on hydraulic uncertainties model (in Chinese). J. Hydraul. Eng. 1992, 5, 33-38.

(C) 2012 by the authors; licensee MDPI, Basel, Switzerland. This article is an open access article distributed under the terms and conditions of the Creative Commons Attribution license (http://creativecommons.org/licenses/by/3.0/). 